\title{
Using Photo-Diary Interviews to Study Cyborgian Identity Performance in Virtual Worlds*
}

\author{
Ulrike Schultze \\ Southern Methodist University \& Lund University \\ PO Box 750333, Dallas TX, 75205, U.S.A. \\ uschultz@smu.edu
}

\begin{abstract}
People's identities (i.e., who they are) are increasingly performed in both physical and digital spaces. Individuals become cyborgs as they extend their presence and bodily senses through digital bodies (e.g., social media profiles, blog posts and avatars). To gain insight into how people make sense of who they are in the face of their digital extensions, a photo-diary method is advanced in this paper. Using a single photo-diary entry and its associated interview, this short paper illustrated empirically the material and discursive practices a user of the virtual world, Second Life, enacted to dynamically draw boundaries to construct her and her avatar's identities.
\end{abstract}

Keywords: cyborg, photo-diary method, performative identity, material and discursive practices.

\section{Introduction}

People's identities (i.e., who they are) are increasingly hybrid, simultaneously performed in physical and digital spaces with physical and digital material. Using technological platforms such as Facebook, Twitter, YouTube and virtual worlds, more and more people rely on digital material to present themselves in multiple settings. They are cyborgs, that is, human beings whose presence and senses are extended through technology [1] and whose identities are entangled with it $[2,3]$.

The type of cyborg that is particularly prevalent in our contemporary computermediated world is the individual extended by digital bodies, ranging from traces of online transactions through blog posts and social media profiles to 3D avatars. As cyborgs many users find themselves entangled with these digital bodies and operating in a space where distinctions between the on- and the off-line and between the "real" and the virtual are increasingly blurred [4].

\footnotetext{
* Funding from the National Science Foundation, Grant IIS-0848692, made this research possible. Any opinions, findings, and conclusions or recommendations expressed in this material are those of the authors and do not necessarily reflect the views of the National Science Foundation. I am also deeply indebted to the research participants for fully embracing this study and sharing their experiences and insights openly.
} 
The purpose of this research is to gain insight into how people make sense of who they are in the face of their digital extensions. To this end, a study of users of the virtual world, Second Life (SL), was conducted using a photo-diary interview method. The purpose of this short paper is to illustrate the photo-diary method and its application in the study of cyborgian identity performance.

\section{Cyborgian Identity}

Even though identity is typically seen as the answer to such questions as "who am I?" and "what am I like?" [5], there are different theoretical perspectives on what identity is. Broadly speaking, identity is either conceptualized in representational or performative terms [6]: the former regards identity as a more or less stable object (i.e., a self) that is carefully performed for others in an act of impression management [7], whereas the latter regards identity as an ongoing process of identification in which an individual is performed by (and subjected to) the material and discursive conditions that are operating it a given social space [8].

In the context of computer-mediated communication, much prior research has adopted a representational lens, separating on-line from off-line identity [9, 10]. Virtual bodies are conceptualized as passive, disembodied signifiers that refer to and are separated from - the 'real' thing, namely, the user's physically embodied self [11]. This suggests a unidirectional relationship in which the user controls his/her virtual re-presentation.

In contrast, the cyborgian notion of identity implies a performative orientation in that it regards the physically and digitally embodied user as entangled. This means that the two interacting bodies - one flesh and blood, the other digital - that constitute the cyborgian user, form a single system, or assemblage [12]. However, the bodies in this entanglement "are not objects with inherent boundaries and properties; they are material-discursive phenomena" [12: 823]. In other words, the boundaries between them are always in the making and the result of material-discursive practices.

To illustrate the boundary-drawing practices through which cyborgian identities are performed, Nyberg [3] presents an example from a call center. To a customer, the components that comprise the service delivery (i.e., the telephone system, the computer systems, the customer service representative, etc.) are experienced as an entangled whole until customer service representatives distance themselves from the (failing) technology with such utterances as "the computer has a mind of its own" or "it is not happy." By means of such performative utterances, identities, properties and agency are materialized.

\section{Photo-Diary Interview Method}

Diaries that are solicited for research purposes are not so much intimate journals as contemporaneous, personal records kept by individual research participants 
themselves [13]. Diarists essentially take on an adjunct-ethnographer role, observing and recording their own performances and well as those of the people around them at or close to the time that events unfold [14]. As such, diary methods are particularly useful in situations where first-hand observations are not possible [15], e.g., in computer-mediated environments where participants are simultaneously physically sitting in front of the computer and present in a virtual space.

Diary methods address some of the shortcomings of interview research. Retrospective interviews are subject to the vagaries of memory and thus frequently generate abstracted biographical narratives, idealized accounts and general opinions [13]. Because diaries are kept contemporaneously, diary-based research is better able to capture the specificity of decisions made and actions taken by individuals. They tend to make visible experiences that are often hidden, thus producing more complete and honest accounts than other methods [16]. Thus, like ethnographic methods, diaries are conducive for studying practices.

By recording everyday incidents in their diaries, participants' consciousness is raised about the things that happen, their surroundings and their interactions with others. Making sense of these events frequently entails the kind of self-reflexive identity work Giddens [17] describes, as diarists narrativize what they did and why in an effort to construct an authentic, coherent self [18]. As such, diaries can be seen not only as a contemporaneous record of events, but also a situated, storied construction of the diarist and the social reality around him/her [13]. They provide insights into the linguistic, cultural and material resources on which diarists draw in their narrativization, thus making diaries conducive for studying identity performatively.

The "photo-diary: diary interview" method [19] — referred to here simply as the photo-diary interview method - combines visual representations (photos), diaries (written text), and interviews (verbal interactions), in an effort to elicit as complete an account possible of diarists' experiences. In particular, images can make different parts of human consciousness, such as tacit knowledge, accessible to both the researcher and the interviewee because they address the limitations of language [20].

Furthermore, by incorporating snapshots of the space in which events took place, the material conditions of incidents (e.g., the configuration of the space, how people were positioned vis-à-vis objects and others, their gestures and what they were wearing), which are frequently left out of textual diary descriptions, become part of the record. In this way, the role of material resources and practices in the performance of identities can be investigated more readily.

\section{Studying Cyborgian Identity Performance in Second Life}

In order to illustrate the photo-diary method, this paper relies on data from a single photo-diary entry drawn from a study of the avatar-self relationship in Second Life (SL), for which 35 participants were interviewed between July 2008 and March 2010. 
Each participant lived in the southwestern United States and spent at least 10 hours a week in-world. The data collection method was intended to gain maximal insight into the participants' own understanding of their identity performance in-world. It proceeded in two phases:

- Initial 2-hour, face-to-face interview: This interview was held in a wi-fi equipped bookstore so that the interviewee could log into SL. A key objective of the face-toface meeting was to acknowledge the role of physical embodiment in cyborgian identity. Furthermore, this in-person encounter was intended to build rapport and trust between the researcher and each participant.

- Weekly photo-diaries (for 3 weeks), which provided the basis for interviews: Photo-diary interviews [19] were conducted by phone and took about 1 hour each. Participants were asked to proceed with their SL activities as they normally would, but to take at least five snapshots a week of incidents that were in some way meaningful, significant or important to them. These snapshots were then pasted into a researcher-supplied photo-diary template, which outlined the annotation questions, i.e., the when, what, why, who, and how for each incident. The incidents documented in the photo-diary were then used as the basis for intensive interviewing.

Participants were recruited via SL groups that had some association with the targeted geographic area. Participants were paid \$150 after completion of the interviews. With the participants' permission, all interviews were tape-recorded.

\subsection{Data Analysis: Dialogic Narrative Analysis}

Viewing the interview as a dialog in which narratives that construct and reconstruct the teller's cyborgian identity are co-created by the investigator and the participant, a dialogic narrative analysis approach was adopted. Dialogic narrative analysis focuses not purely on the content and structure of the text (i.e., "what" was said and "how"), but also on "to whom" it was said and "why" [18]. Furthermore, it regards the interview as a local accomplishment within a given interview scene in which situated and morally adequate accounts of the interviewee are produced [21].

\section{Empirical Illustration: Abigail as Independent Agent}

As Abigail ${ }^{1}$ and Ozman, their avatars, Terry and Daniel had met, fallen in love and married in SL. They then married in real life (RL) also. They both worked in

\footnotetext{
${ }^{1}$ To protect the participants' identities, all names are pseudonyms and the photo-diary image was converted to a line drawing using an image editor.
} 
IT-related jobs in RL and ran businesses in SL. Abigail had a photography studio, specializing in profile images and promotional material. She was forty and had been in SL for 22 months at the time of the interview.

The photo-diary entry (Figure 1) was part of her second photo-dairy. The entry focuses on Terry's experience of her avatar, Abigail, as an independent being. This incident was prompted by the material conditions of the technology: Abigail appeared on the screen as a virtual body independent of Terry's control at the keyboard. Thanks to the animations embedded in SL objects, Abigail looked alive as she was sitting on the swing, playing with her necklace and gazing in different directions.

Looking at this image in Figure 1, it is not surprising that Terry attributed a cognitive and emotional life world to her avatar. Indeed, she sensed that her avatar was deep in thought and, drawing an analogy between this serendipitous encounter with Abigail and a RL "sweet moment" in which one observes another without being noticed, she wanted to "cherish" the moment rather than disturb her. Terry experienced a deep sense of love for and emotional connection with her avatar. She believed that she could read Abigail's mind and sense her emotional state.

Discursively Terry made a clear distinction between herself and Abigail by referring to herself in the first person ("I"), while referring to Abigail by name and in the third person. Additionally, she referred to the Abigail's life-world as "SLife," thus materializing a cut between "real" and "second" life.

She also relied on the third person ("you" as a surrogate for "one") to universalize the experience of 'capturing someone in a sweet moment.' In this way, she turned this very personal encounter with her avatar and her feelings of love for and connectedness with her digital body into an experience potentially shared by everyone. This discursive strategy normalizes what might otherwise be a contestable claim, making this assertion more credible to both Terry and others.

The photo-diary interview revealed additional insights into how Terry made sense of her cyborgian identity. The first part of the interview related to Figure 1is presented in its totality below, albeit in sections for ease of interpretation. In line with the tenets of dialogic narrative analysis, the interviewer's utterances, identified by initials, are included in the transcripts. 


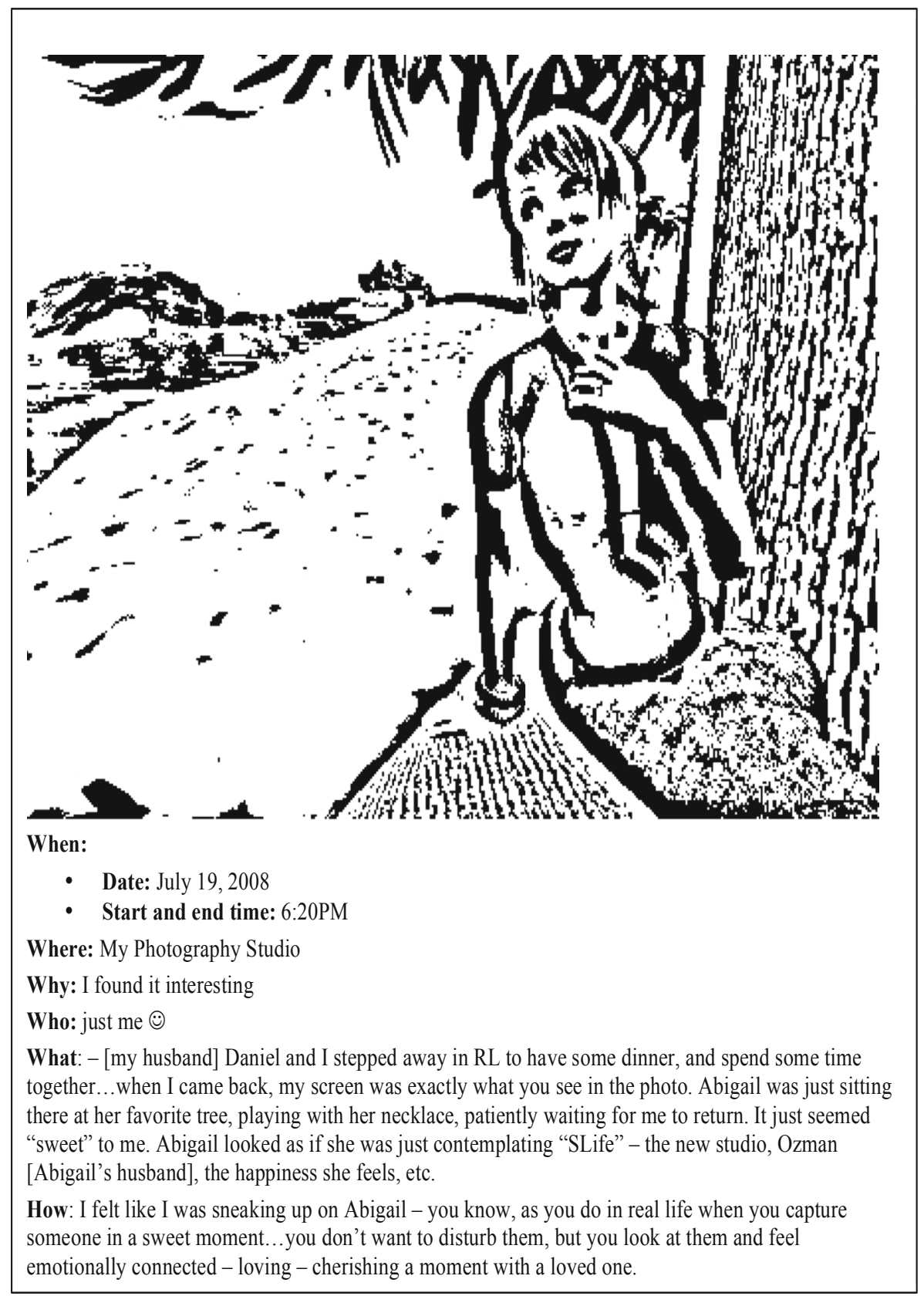

Fig. 1. "Sneaking up on Abigail” Photo-Diary Entry 
U.S.: $\quad$ So, your first picture really, really stunned me.... Tell me about it.

Terry: Well, I thought it was interesting because, you know, Daniel and I were in Second Life. I was doing something. I was just sitting on the tree. I think I was actually talking with someone before then and I just left Abigail sitting on the pose ball, and I had zoomed in on that, just in that general area, and then walked away. We walked away, had some dinner, spent some time together. I said, "Okay, well I think I'm gonna go back to my computer now." It just seemed like she was just sitting there, just patiently waiting, just looking in different directions, playing with her necklace. And it really did seem like I was kinda sneaking up on her. I didn't want to disturb her (laughing).

U.S.: (laughing) So, was that the first time you sort of really saw her as this, I mean, it seems like an independent person? ... or, is that not how you felt in this picture?

Terry: Yes. As a matter of fact, Abigail is -- well I guess. I mean, it just seemed like at that moment, Abigail was Abigail, in her self. And I had, you know, I really had nothing to do with controlling her avatar at that point or you know, controlling the shot, or anything like that. It just seemed like she was just sitting there, patiently waiting for me to come back (laughing).

Fig. 2. Photo-Diary Interview Excerpt 1

Notable about Terry's narration of the events that led up to the photo-diary entry (Figure 2), is that the boundaries between RL and SL, as well as between herself and Abigail were ambiguous. Initially, she used "I" to refer to herself acting through Abigail in SL ("I was sitting on a tree"). However, she quickly moved to describing her interaction with her avatar in more technical terms. She referred to "sitting" Abigail "on a pose ball" and "zooming" the camera into "that general area" where Abigail was seated. This suggests that the extent to which such material practices as clicking "sit" options on pose balls and training the camera on a certain scene are salient to the user, they enact boundaries between users and their avatars. In these material practices, the avatar is a technological artifact.

However, the separation between her and Abigail deepened when Terry saw the avatar acting ("looking in different directions, playing with her necklace") without Terry "controlling" either the virtual body or "the shot" (i.e., camera). At this point, Terry acknowledged "Abigail was Abigail, in herself." In addition to bestowing a self to the avatar, she suggested that as an independent, living being, Abigail had a digital body through which she manifested herself (i.e., "I really had nothing to do with controlling her avatar"). In other words, Abigail was accorded a mind, body and identity distinct from Terry's. 
U.S.: (laughing) And how did that make you feel?

Terry: Oh! I just thought it was sweet. It's endearing to me. Because I have, you know, obviously, I have connected with the avatar, Abigail. And you know, it's almost as if she's my child or something. And when I walked up and saw Abigail just sitting there, I really didn't want to disturb her. I just felt like, “Oh!” you know, "how sweet!" (laughing) So, I really just kinda felt full at the moment. I felt, you know, full of pride. It just kind of helped me to think about all of those things that are going on in Second Life and just started thinking about, you know, "Wow! We've really come a long way on the studio" and Abigail is just so happily married to Ozman. And, it just broadened my thinking a little bit, I think.

Fig. 3. Photo-Diary Interview Excerpt 2

In the next section of the interview (Figure 3), Terry tried to make sense of her connection to an avatar that she has just described as an independent being. She drew on the mother-child relationship ("sweet" and "full of pride") to describe the emotional connection with her avatar. However, instead of being proud of herchild Abigail's accomplishments, she was proud of their joint accomplishments in SL (i.e., "we've really come a long way"). In other words, the mother metaphor allowed her to own some of Abigail's accomplishments - and the pride that went with it -- for herself.

U.S.: You're thinking on what, specifically? I mean, just her life in general or ...?

Terry: Yes, it was just a reflective thought, I think. Just reflecting on the time that I've spent in SL. The time that has gone into building this new island and the new studio and everything. And you know, there comes a pride with something that you create and you get so close to being finished, and you just have to stand back and look at it and say, "Wow! This really turned out nice." I think that in that moment for me, it was "Okay, we're about to open the studio and I think I've done the right thing, and Abigail thinks so too." (laughing)

Fig. 4. Photo-Diary Interview Excerpt

As the interview continued (Figure 4), Terry shifted attention away from Abigail onto herself for a while. She acknowledged that she, Terry, was contemplating her life in SL and that she felt proud of growing her business by building a new photographic studio, which was about to open. However, she again relied on the discursive strategy of the third person "you" to universalize the experience of "feeling pride for something you created.' Thus, through the course of the interview she was working her way towards legitimating the pride she felt of her own accomplishments, by first attributing this pride to her child Abigail and then universalizing it. 
At the end of this excerpt, Terry re-introduced Abigail as an independent agent. Albeit laughingly, she indicated that the avatar approved of Terry's business decisions (i.e., "I think I've done the right thing, and Abigail thinks so too"). This might be seen as an attempt to return to the identity narrative of Abigail as a living, thinking and feeling being.

U.S.: $\quad$ So is it almost like you're feeling that you as Terry, are in some ways the owner of all that you have created in Second Life, and Abigail just sort of being an onlooker in this sense?

Terry: Yes, it could be. I think that I sometimes feel like I'm the onlooker (laughing) and Abigail is the one doing all the creation. But yes, I mean, I guess for the real part of me is just -- I'm a creative person anyway and to be able to have an outlet for creativity in this way, it allows me to think more in terms of just, you know, not a 2D image. I can't draw for anything but I have all of these thoughts in my head and to be able to actually create something in 3D and say, "This is what I wanted it to look like." It just really brings a lot of really good thoughts and good moments for me to sit back and say, "Wow! That's pretty cool!" (laughing)

Fig. 5. Photo-Diary Interview Excerpt 4

In this final section of the interview (Figure 5), the interviewer pressed Terry on agency, especially to whom she attributed ownership of the creative content in SL. After initially wavering ("I sometimes feel like I'm the onlooker ... and Abigail is the one doing all the creation"), Terry later conceded that she was "a creative person" with "all of these thoughts in my head." SL served as her outlet because she "can't draw for anything." Being able to see her creativity materialize in 3D then allowed her to acknowledge that her ideas are "pretty cool." Again, Abigail disappeared during this narrative as Terry's identity as the creative power behind her SL business emerges.

\section{Conclusion}

The objective of this short methodology paper was to illustrate the utility of the photo-diary interview method for studying cyborgian identity performance. Adopting a performative rather than a representational conceptualization of identity performance, this paper focused on identifying the material and discursive practices through which situated and dynamic distinctions are made between the user's physical and virtual embodiments, between reality and virtuality and between human an nonhuman agency. The empirical illustration demonstrates users' ongoing negotiation of these boundaries as they try of make sense of who they are in light of their increasing entanglement with virtual bodies. The photo-diary interview method is conducive for identifying both the digital materiality and their meanings that users relied on to enact an identity in Second Life, as well as the material and discursive practices through which identities were performed. 


\section{References}

1. Borer, M.I.: The Cyborgian Self: Toward a Critical Social Theory of Cyberspace. Reconstruction: Studies in Contemporary Culture, vol. 2 (2002)

2. Introna, L.D.: Towards a Post-Human Intra-Actional Account of Socio-Technical Agency (and Morality). Moral Agency and Technical Artefacts. NIAS, Hague (2007)

3. Nyberg, D.: Computers, Customer Service Operatives and Cyborgs: Intra-actions in Call Centres. Organization Studies 30, 1181-1199 (2009)

4. Hardey, M.: Life Beyond the Screen: Embodiment and Identity through the Internet. The Sociological Review 50, 570-585 (2002)

5. Chatman, C.M., Eccles, J.S., Malanchuk, O.: Identity Negotiation in Everyday Settings. In: Downey, G., Eccles, J.S., Chatman, C.M. (eds.) Navigating the Future: Social Identity, Coping and Life Tasks, pp. 116-139. Russell Sage Foundation, New York (2005)

6. Gregson, N., Rose, G.: Taking Butler Elsewhere: Performativities, Spatialities and Subjectivities. Environment and Planning D: Society and Space 18, 433-452 (2000)

7. Goffman, E.: Behavior in Public Places: Notes on the Social Organization of Gatherings. Free Press, New York (1963)

8. Butler, J.: Gender Trouble: Feminism and the Subversion of Identity. Routledge, New York (1990)

9. Turkle, S.: Life on the Screen: Identity in the Life of the Internet. Simon \& Shuster, New York (1995)

10. Bessiere, K., Seay, A.F., Kiesler, S.: The Ideal Elf: Identity Exploration in World of Warcraft. Cyber Psychology \& Behavior 10, 530-535 (2007)

11. Bardzell, J., Bardzell, S.: Intimate Interactions: Online Representation and Software of the Self. Interactions, 11-15 (2008)

12. Barad, K.: Posthumanist Performativity: Toward an Understanding of How Matter comes to Matter. Signs: Journal of Women in Culture 28, 801-831 (2003)

13. Alaszewski, A.: Using Diaries for Social Research. Sage, Thousand Oaks (2006)

14. Zimmerman, D.H., Wieder, D.L.: The Diary: Diary-Interview Method. Urban Life 5, 479-498 (1977)

15. Czarniawska, B.: Shadowing and Other Techniques for Doing Fieldwork in Modern Society. Liber, Copenhagen (2007)

16. Kenten, C.: Narrating Oneself: Reflections on the Use of Solicited Diaries with Diary Interviews. Forum: Qualitative Social Research 11, Article 16 (2010)

17. Giddens, A.: Modernity and self-identity: Self and society in the late modern age. Polity Press, Cambridge (1991)

18. Riessman, C.K.: Narrative Methods for the Human Sciences. Sage, Thousand Oaks (2008)

19. Latham, A.: Research, Performance and Doing Human Geography: Some Reflections on the Diary-Photograph, Diary-Interview Method. Environment and Planning A 35, 1993-2017 (2003)

20. Bagnoli, A.: Beyond the Standard Interview: The Use of Graphic Elicitation and ArtsBased Methods. Qualitative Research 9, 547-570 (2009)

21. Alvesson, M.: Beyond Neopositivists, Romantics, and Localists: A Reflexive Approach to Interviews in Organizational Research. Academy of Management Review 28, 13 (2003) 